\title{
BMJ Open Maternal perceptions of underweight and overweight for 6-8 years olds from a Canadian cohort: reporting weights, concerns and conversations with healthcare providers
}

\author{
Sheila W McDonald, ${ }^{1,2}$ Heather K Ginez, ${ }^{1}$ Angela E Vinturache, ${ }^{1}$ \\ Suzanne C Tough ${ }^{1,3}$
}

To cite: McDonald SW, Ginez HK, Vinturache AE, et al. Maternal perceptions of underweight and overweight for 6-8 years olds from a Canadian cohort: reporting weights, concerns and conversations with healthcare providers. BMJ Open 2016;6: e012094. doi:10.1136/ bmjopen-2016-012094

- Prepublication history for this paper is available online. To view these files please visit the journal online (http://dx.doi.org/10.1136/ bmjopen-2016-012094).

Received 1 April 2016 Revised 21 July 2016 Accepted 7 September 2016

CrossMark

For numbered affiliations see end of article.

Correspondence to Dr Angela Vinturache; angela_wintu@shaw.ca

\section{ABSTRACT}

Objectives: The majority of mothers do not correctly identify their child's weight status. The reasons for the misperception are not well understood. This study's objective was to describe maternal perceptions of their child's body mass index (BMI) and maternal report of weight concerns raised by a health professional.

Design: Prospective, community-based cohort. Participants: Data were collected in 2010 from 450 mothers previously included in a longitudinal birth cohort. Mothers of children aged 6-8 years reported their child's anthropometric measures and were surveyed concerning their opinion about their child's weight. They were also asked if a healthcare provider raised any concerns regarding their child's body weight. Child BMI was categorised according to the WHO Growth Charts adapted for Canada. Descriptive statistics and bivariate analyses were used to evaluate mothers' ability to correctly identify their children's body habitus.

Results: $74 \%$ of children had a healthy BMI, $10 \%$ were underweight, $9 \%$ were overweight and $7 \%$ were obese. $80 \%, 89 \%$ and $62 \%$ of mothers with underweight, overweight and obese children, respectively, believed that their child was at the right weight. The proportion of mothers who recalled a health professional raising concerns about their child being underweight, overweight, and obese was low (12.5\%).

Conclusions: The majority of mothers with children at unhealthy weights misclassified and normalised their child's weight status, and they did not recall a health professional raising concerns regarding their child's weight. The highest rates of child body weight misclassification occurred in overweight children. This suggests that there are missed opportunities for healthcare professionals to improve knowledge exchange and early interventions to assist parents to recognise and support healthy weights for their children.

\section{INTRODUCTION}

Increasing rates of childhood overweight are a societal concern given the trajectory of

\section{Strengths and limitations of this study}

- This study explored mothers' perceptions of child body status as well as their experiences with healthcare providers concerns regarding optimal child body weight.

- Pilot testing of the survey showed the appropriateness of the questions to the target population and the reliability of the questionnaire.

- The cohort is representative for the Canadian population and best generalised to middle- and high-income families in urban settings.

- Child anthropometric measures were reported by mothers; no objective measure of children's weight status was available.

adverse health impacts into adulthood. According to WHO standards, rates of overweight and obesity were estimated at $32.8 \%$ and underweight at 2.2\% for Canadian children aged 5-11 years between 2009 and 2011. ${ }^{1}$ Obesity in children and adolescents has been linked to sustained weight problems and related morbidities and mortalities throughout the life course including dyslipidemia, type 2 diabetes, metabolic syndrome, coronary heart disease and hypertension. $^{2-4}$ On the other hand, restrictive eating disorders, while at much lower prevalence rates (2.6 out of $1000005-12$ years olds), also have significant morbidities and mortalities associated with extreme low body weights. ${ }^{5}{ }^{6}$ Children who are overweight or obese may be at higher risk for bullying and exclusion from play with negative mental health outcomes. ${ }^{7-9}$ Effective weight management care is needed to help children achieve improved health and wellness, with the family and the family-health professional relationship having a profound impact for paediatric weight management. ${ }^{10} 11$ Of note, 
families have identified a preference for healthcare providers to inform them about child-related health information. ${ }^{12}$

Parents and families play a vital role in supporting healthy weights for children. ${ }^{13}{ }^{14}$ Parents concerned about their children's weights are more likely to take action to improve weight status such as limiting screen time, increasing physical activity, and improving children's diets and nutrition. ${ }^{14}$ Practices such as eating together as a family and limiting the time spent alone at home after school have been shown to protect against high body mass index (BMI). ${ }^{13}$

Nevertheless, studies from the UK, Norway, Germany, Portugal, Italy, Israel, Australia, Mexico, the USA and Canada have demonstrated that parents have low recognition of unhealthy weights in their own children with the majority of studies reporting that between $50 \%$ and $94 \%$ of parents of overweight children fail to identify their child as overweight, and $65 \%$ of parents of underweight children fail to identify their child as underweight. ${ }^{15-28}$ Less than $50 \%$ of parents understood that there are physical and mental health problems associated with unhealthy weights. ${ }^{28}{ }^{29}$ A recent systematic review concurs that mothers have difficulty perceiving the nutritional status of their children. This finding indicates a need for additional studies that would first, elucidate how mothers perceive their child's body weight and second, how risk communication about weight, nutrition and health is perceived. ${ }^{14} 30$

Few studies have examined the awareness of Canadian parents and their perceptions of interactions with the universal healthcare system related to their child's weight status. An Ontario study from 2007 revealed that $63 \%$ of parents with overweight or obese children inaccurately identified their child's weight status. ${ }^{19}$ Furthermore, since excess or suboptimal weight is under-recognised, parents may not receive evidencebased strategies to address weights, and interventions to support children may not be identified. Given that mothers may not perceive their children's weight status, effective communication from healthcare providers is essential to improving parental health literacy. ${ }^{31}$ Healthcare providers need to determine child nutrition status and ascertain parents' perception of their child's body weight in order to provide specific parental counselling and education. Parental perception of children's BMI and their ability to recall health provider information are critical in understanding knowledge exchange that occurs in clinical care.

The objective of this study was to explore parental perception of BMI of their child aged 6-8 years and their report of concerns about weight raised by a health professional in a longitudinal cohort from Alberta, Canada.

\section{METHODS}

The Community Perinatal Care (CPC) study recruited pregnant participants between 2001 and 2004 into a randomised control trial of prenatal care supports. ${ }^{32} 33$ Women were recruited from three low-risk maternity clinics in the urban centre of Calgary, Alberta, Canada and were subsequently invited to participate in follow-up studies as their children turned 3 and 5 years old. ${ }^{33-35}$ In 2009, mothers who had participated in previous data collection waves were contacted and invited to participate in another follow-up study when their children were between 6 and 8 years of age. Data collection began in January 2010 and finished in June the same year. Questionnaires were mailed to 706 women. A total of 450 completed questionnaires were returned for a final response rate of $64 \%$ (figure 1).

\section{Measures}

Families were provided with tape measures and instructions for taking their child's anthropometric measurements at survey mail-out. BMIs were calculated from the maternal reports of child's height and weight and categorised according to WHO Growth Charts for Canada for the appropriate gender and age ranges between 6 and 8 years. Overweight BMIs were the 85-97th centiles, obese BMIs were above the 97 th centile and underweight BMIs were below the 3 rd centile. ${ }^{36}$

Mothers were asked if they thought their child should weigh less, was about the right weight or should weigh more. A second question asked if they recalled a health professional rising concerns about their child's weight. The questionnaire was pilot-tested with 10 women with children of similar age to the cohort and revised for unclear wording. The final survey took $\sim 20-25 \mathrm{~min}$ to complete and collected the height and weight of children through maternal self-report, in addition to other lifestyle, health and demographic information. Women were provided with a one-time recreation pass in appreciation for their time that was mailed with the questionnaire with a postage-paid envelope to facilitate return of the questionnaire.

\section{Data analysis}

Descriptive analysis of participant characteristics, including demographics and healthcare utilisation, was undertaken. The proportion of mothers who correctly identified their child's weight status was calculated. The proportion of children who had BMIs outside the normal range was calculated. The proportions of 'correct' responses for each weight category were described. Finally, the proportion of those who recalled a conversation with a healthcare provider by child's BMI was described. Bivariate comparisons were conducted using $\chi^{2}$ test. Data were analysed using the IBM SPSS statistical software program (V.20.0).

Of note, there were no clinically meaningful differences between those randomised to the prenatal care supports and controls in the original trial, so the analysis did not control for intervention group. In addition, the intervention ended at delivery, and further engagement 


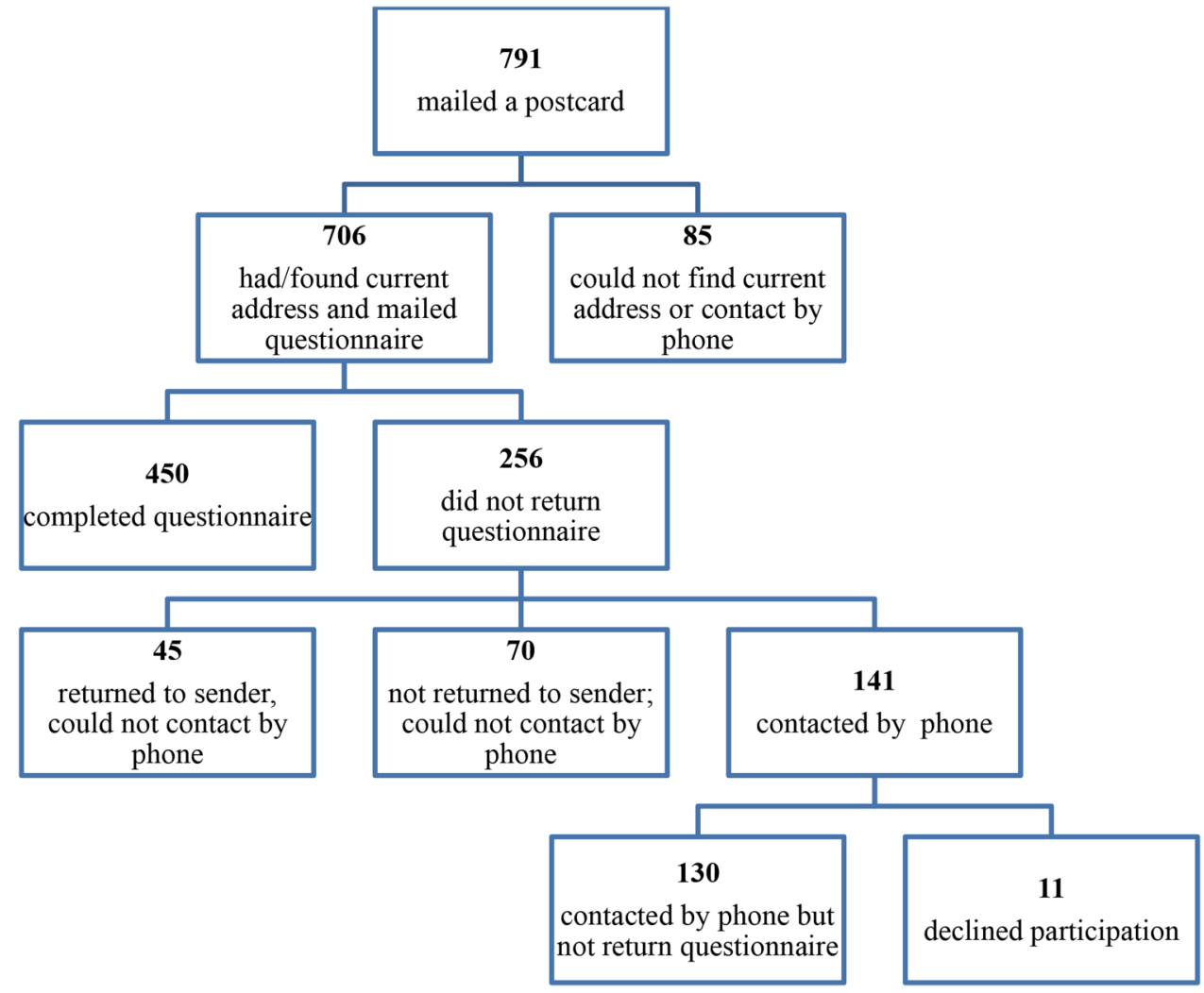

Figure 1 Study flow chart mapping eligibility and recruitment of mothers who participated in the follow-up study at the age of 6-8 years.

was identical for all participants and entailed completion of a questionnaire.

\section{Consent}

Informed consent was obtained from the study participants at the time of recruitment.

\section{RESULTS}

Forty-nine percent of children in the study were male. The mean age for children was 7.4 years $(\mathrm{SD}=0.6)$ and for mothers 38.9 years $(\mathrm{SD}=4.5)$. According to calculated BMI levels, $25.9 \%$ of children had unhealthy BMIs, with $9 \%$ of children in the overweight category, $7.2 \%$ in the obese category and $9.7 \%$ in the underweight category, while the remaining $74.1 \%$ fell into the normal weight category (table 1).

Mothers were mostly married or living common law $(93.6 \%)$, had a household income above \$80000 $(63.5 \%)$ and had finished some level of post-secondary education $(74.3 \%)$. Over half were employed $(53.3 \%)$ (table 1).

Table 2 summarises the survey data on parental perceptions of their child's health. More than $87 \%$ of children were reported to be in very good to excellent health, and $84.5 \%$ of mothers were satisfied or highly satisfied with their child's physical activity levels. Overall, $88.2 \%$ of mothers thought their child was about the right weight, and $11.8 \%$ had concerns about their child's weight. Over $95 \%$ reported having a regular family doctor or paediatrician, and $75 \%$ had seen them in the recent past. Approximately $4 \%$ of parents recalled a healthcare provider raising concerns about their child's weight. Although $25.9 \%$ of children had unhealthy BMIs, $95.8 \%$ of mothers reported that no concerns had been raised (table 2 ).

As shown in table 3, almost three-quarters of mothers $(72.8 \%, 292 / 401)$ correctly identified their child's weight status. However, among mothers of children with unhealthy weights, only $18.3 \%(19 / 104)$ correctly identified their child's unhealthy weight status. Healthcare provider concerns were reported for only $12.5 \%$ of children with unhealthy weights. Among mothers of underweight children, $79.5 \%$ reported their child's weight to be about right and only $12.8 \%$ recalled healthcare providers raising concerns. Among the mothers with overweight children, $89 \%$ reported that their child was about the right weight and only $5.6 \%$ recalled a healthcare provider raising concerns. Among mothers of obese children, $62.1 \%$ thought their child was the right weight and $17.9 \%$ recalled a healthcare provider saying their child should weigh less. Finally, among mothers of children deemed to have a healthy weight, $2 \% \quad(n=6)$ recalled that concerns were raised, of which the majority $(67 \%)$ were related to the child being underweight (table 3 ).

Among the 47 mothers who identified that their child should weigh either more or less, only $4.7 \%(19 / 401)$ 
Table 1 Characteristics of study participants $\left(\mathrm{N}=450^{*}\right)$

n $\%$

\section{Children}

\begin{tabular}{|c|c|c|}
\hline Age (years) (mean $\pm S D$ ) & $7.4 \pm 0.6$ & \\
\hline Gender male & 219 & $48.7 \%$ \\
\hline \multicolumn{3}{|l|}{ BMI status } \\
\hline Underweight (<3rd centile) & 39 & $9.7 \%$ \\
\hline Normal weight (3rd-85th centiles) & 297 & $74.1 \%$ \\
\hline Overweight (>85th-97th centiles) & 36 & $9.0 \%$ \\
\hline Obese ( $\geq 97$ th centile) & 29 & $7.2 \%$ \\
\hline \multicolumn{3}{|l|}{ Mothers } \\
\hline Age (years) (mean $\pm S D)$ & 38.9 & 4.5 \\
\hline \multicolumn{3}{|l|}{ Marital status } \\
\hline Married/common law & 421 & $93.6 \%$ \\
\hline Divorced/separated & 24 & $5.3 \%$ \\
\hline Single/widowed & 5 & $1.1 \%$ \\
\hline \multicolumn{3}{|l|}{ Main activity } \\
\hline Employed or self-employed & 237 & $53.3 \%$ \\
\hline Homemaker & 188 & $42.2 \%$ \\
\hline Other & 20 & $4.5 \%$ \\
\hline \multicolumn{3}{|l|}{ Household income } \\
\hline$\leq \$ 40000$ & 22 & $4.9 \%$ \\
\hline$\$ 40000-\$ 79999$ & 85 & $18.9 \%$ \\
\hline$\$ 80000-\$ 119999$ & 136 & $30.3 \%$ \\
\hline$\$ 120000-\$ 159999$ & 65 & $14.5 \%$ \\
\hline$\geq \$ 160000$ & 84 & $18.7 \%$ \\
\hline Prefer not to answer & 57 & $12.7 \%$ \\
\hline \multicolumn{3}{|l|}{ Education } \\
\hline High school or less & 44 & $9.8 \%$ \\
\hline Some college, trade or university & 72 & $16.0 \%$ \\
\hline College/trade & 102 & $22.7 \%$ \\
\hline University & 171 & $38.0 \%$ \\
\hline Post graduate studies & 61 & $13.6 \%$ \\
\hline
\end{tabular}

\begin{tabular}{|c|c|c|}
\hline & $\mathbf{n}$ & $\%$ \\
\hline \multicolumn{3}{|l|}{ Health status } \\
\hline Very good to excellent & 394 & 87.8 \\
\hline Good & 47 & 10.4 \\
\hline Fair to poor & 8 & 1.8 \\
\hline \multicolumn{3}{|c|}{ Satisfaction with child's physical activity levels } \\
\hline Satisfied or highly satisfied & 376 & 84.5 \\
\hline Neutral & 44 & 9.9 \\
\hline Dissatisfied or highly dissatisfied & 25 & 5.6 \\
\hline \multicolumn{3}{|l|}{ Mother concerns about child's weight } \\
\hline Yes & 53 & 11.8 \\
\hline No & 397 & 88.2 \\
\hline \multicolumn{3}{|c|}{$\begin{array}{l}\text { Recall healthcare provider raising concerns about child's } \\
\text { weight }\end{array}$} \\
\hline Yes & 19 & 4.2 \\
\hline No & 429 & 95.8 \\
\hline \multicolumn{3}{|c|}{ Routine health examination with GP in last year } \\
\hline Yes & 338 & 75.1 \\
\hline No & 112 & 24.9 \\
\hline
\end{tabular}

were correct based on the child's having a BMI that was not in the normal range. Half of concerns were for normal weight children. Among the 14 mothers who reported their child should weigh less, $85.7 \%$ were correct. Among the 33 mothers who reported their child should weigh more, just $21.2 \%$ were correct as the majority of mothers reporting this concern had children already in the normal weight range. Nineteen $(4.2 \%)$ mothers reported conversations with the healthcare provider about child's weight. Among the small number of mothers who recalled a healthcare provider conversation about their child's body weight, almost $78 \%$ accurately recalled that the conversation was about their child being overweight and $\sim 37 \%$ inaccurately recalled the discussion about the child's weight status (table 4).

\section{DISCUSSION}

In this study, parents of children aged $6-8$ years were asked about their child's body weight and to recall if they remembered a healthcare provider raising concerns. Our findings suggest that those mothers with normal weight children were most likely to identify their child as a 'healthy' weight. Of note, when concerns were raised for normal weight children, mothers often thought that their children should weigh more. However, between $62 \%$ and $89 \%$ of mothers with children who were obese or overweight, respectively, incorrectly identified their child as 'about the right weight'. The highest rate of misclassification occurred for overweight children. Furthermore, $<18 \%$ of mothers with children in the underweight, overweight or obese category for BMI recalled having a conversation with a healthcare provider about their child's weight, and recall was particularly low if the child was overweight

Obesity is prevalent in children of all ages in North America and other developed countries. Evidence shows that BMIs between the ages of 6 and 8 years are important predictors of adult obesity and associated health risks. ${ }^{1}$ High rates of maternal misperceptions of their child's unhealthy body weight status have been reported in several studies. ${ }^{30}$

Overall accuracy of weight identification in this Alberta-based study (73\%) was somewhat higher than that in the 2007 study in Ontario, which reported $62 \%$ accuracy, yet both studies show that parents have misperceptions regarding their children's weight status. Discrepancies could be due to different definitions and methodologies. ${ }^{19}$ Similar findings were found in a study of 223 children aged 2-17 years, attending paediatric practices in Chicago, USA. ${ }^{37}$ Accurate identification of weight problems for children who were underweight, overweight or obese was also low. Among mothers with an overweight or obese child, $82 \%$ did not recognise that their child had a BMI that was too high. Similarly, $82 \%$ of mothers with underweight children did not recognise that their child had a BMI that was too low. ${ }^{37}$ Mothers of overweight children, in particular, had 
Table 3 BMI of child and concerns about child's weight

\begin{tabular}{|c|c|c|c|c|c|c|c|c|}
\hline & \multicolumn{2}{|c|}{$\begin{array}{l}\text { Underweight } \\
\text { (<3rd centile) } \\
\mathrm{N}=39\end{array}$} & \multicolumn{2}{|c|}{$\begin{array}{l}\text { Healthy } \\
\text { (3rd-85th } \\
\text { centiles) } \\
\mathrm{N}=297\end{array}$} & \multicolumn{2}{|c|}{$\begin{array}{l}\text { Overweight } \\
\text { (>85th-97th } \\
\text { centiles) } \\
\mathrm{N}=36\end{array}$} & \multicolumn{2}{|c|}{$\begin{array}{l}\text { Obese } \\
\text { ( } \geq 97 \text { th centile) } \\
N=29\end{array}$} \\
\hline & $\bar{n}$ & $\%$ & $\bar{n}$ & $\%$ & $\bar{n}$ & $\%$ & $\bar{n}$ & $\%$ \\
\hline \multicolumn{9}{|c|}{ Mother's opinion of child's weight } \\
\hline Should weigh more & 7 & 17.9 & 23 & 7.7 & 1 & 2.8 & 2 & 6.9 \\
\hline About the right weight & 31 & 79.5 & 273 & 91.9 & 32 & 88.9 & 18 & 62.1 \\
\hline Should weigh less & 1 & 2.6 & 1 & 0.3 & 3 & 8.3 & 9 & 31.0 \\
\hline \multicolumn{9}{|c|}{ Concerns recently raised by a health professional } \\
\hline Child being underweight & 5 & 12.8 & 4 & 1.3 & 1 & 2.8 & 0 & 0.0 \\
\hline No concerns & 34 & 87.2 & 291 & 98.0 & 33 & 91.7 & 23 & 82.1 \\
\hline Child being overweight & 0 & 0.0 & 2 & 0.7 & 2 & 5.6 & 5 & 17.9 \\
\hline
\end{tabular}

difficulties recognising their child's unhealthy weight, with $89 \%$ inaccurately saying that their child was about the right weight. These findings suggest that maternal identification of overweight BMI is the most difficult. Half of mothers with concerns had children who were already at a healthy weight. Among mothers with normal weight children who reported concerns, the majority thought that their child should weigh more. This pattern may reflect a shift in perceptions of higher weights as normal, with more parents inaccurately reporting their child should weigh more to be at a normal weight. ${ }^{15}$

In the present study, recall of healthcare provider concerns about weight was very low. This suggests that healthcare providers may not be raising concerns about $\mathrm{BMI}$ in routine check-ups and other visits, or that concerns are not being communicated in ways that are salient and memorable to mothers. ${ }^{20}$ Previous studies suggest that paediatricians and physicians are a preferred source of weight-related information. ${ }^{20}$ Regular feedback on weight status from schools and healthcare providers has been shown to be positively received by the majority of parents. ${ }^{20} 3839$ However, such conversations can be difficult and time-consuming, and some parents can be defensive, defiant or in denial regarding

Table 4 Accuracy of concerns about child's weight

\begin{tabular}{|c|c|c|c|c|}
\hline & \multicolumn{2}{|c|}{ Accurate } & \multicolumn{2}{|c|}{ Inaccurate } \\
\hline & $\bar{n}$ & $\%$ & $\overline{\mathbf{n}}$ & $\%$ \\
\hline \multicolumn{5}{|c|}{ Mother's opinion of child's weight } \\
\hline Should weigh more & 7 & 21.2 & 26 & 78.8 \\
\hline Should weigh less & 12 & 85.7 & 2 & 14.3 \\
\hline Total & 19 & 40.4 & 28 & 59.6 \\
\hline \multicolumn{5}{|c|}{$\begin{array}{l}\text { Mothers recall of concerns recently raised by a health } \\
\text { professional }\end{array}$} \\
\hline Child being underweight & 5 & 50.0 & 5 & 50.0 \\
\hline Child being overweight & 7 & 77.8 & 2 & 22.2 \\
\hline Total & 12 & 63.2 & 7 & 36.8 \\
\hline
\end{tabular}

this sensitive issue particularly when they have weight concerns of their own. ${ }^{40}$ Approaching the conversation with visual aids or more salient aspects of unhealthy BMIs such as decreased abilities for physical activity and fat folds along with information regarding potential physical and mental health effects may help make conversations about weight concerns more memorable. $^{21} 282940$ Since parents will not seek out assistance for children's weight if they perceive it to be normal, ${ }^{26}$ Canada's universal health system, which includes annual child growth and health assessment, provides an opportunity to have regular conversations with parents concerning weight status with a trusted source assessment. However, weight feedback should also include strategies shown to improve health behaviours such as having a family meal time, healthy eating, and reducing snacking and sedentary activities. ${ }^{41}$

\section{Study limitations}

Our study has limitations. There was no information collected about whether healthcare providers measured the child's BMI during consultations; however, measurements of height and weight are standard clinical practice for child check-up protocol in the Canadian practice. Maternal reports on doctor visits have included routine follow-ups and visits for acute illnesses, and it is less likely that doctors would raise concerns about weight status when the child is acutely ill. Also, we did not collect objective information as to whether the healthcare worker actually raised concerns about the child's weight gain during consultations. However, if mothers do not recall discussion concerning their child's body status could be assumed that either, the issue has not been raised or, if raised, was not memorable.

Another limitation of this study is that height and weight were self-reported by mothers. This introduces potential bias in the study as parent-reported measures for children aged under 11 years often underestimate heights and result in overestimations of overweight and obese BMIs. $^{42}$ Some unconcerned mothers who 
reported weights and heights in the overweight range may have children who are actually in the normal weight range. However, in this study, the proportion of children with overweight or obese BMIs is well below national averages at the time, of $13.1 \%$ obese and $19.7 \%$ overweight. ${ }^{42}$ Consequently, overestimation of overweight in this study is likely to be low. Although the sociodemographic characteristics representative for the population in this study are similar to the Canadian parenting population, the findings from this study are best generalised to middle- and high-income families in urban settings. In addition, pilot testing of the survey showed the appropriateness of the questions to the target population and the reliability of our questionnaire.

\section{CONCLUSIONS}

This study suggests that mothers have difficulty in perceiving their children's weight status, particularly when their child is overweight, and few mothers recall healthcare providers raising concerns about their child's weight. These findings highlight the need for further research to understand parental misperceptions of child growth and risk communication from healthcare providers about child weight. ${ }^{43}$ These results suggest that there are opportunities for healthcare professionals to improve knowledge exchange with parents about the healthy BMI for their child. Raising and repeating concerns about BMI, and discussing patient-specific strategies to improve weight, could support parents in implementing behaviour changes to improve child health. Results in the overweight category indicate that parents need extra support to clarify the distinction between healthy and overweight, especially as overweight status becomes normalised due to increasing prevalence. ${ }^{15}$

\section{Author affiliations}

${ }^{1}$ Department of Paediatrics, Cumming School of Medicine, University of Calgary, Calgary, Alberta, Canada

${ }^{2}$ Population, Public, and Aboriginal Health, Alberta Health Services, Calgary, Alberta, Canada

${ }^{3}$ Department of Community Health Sciences, Cumming School of Medicine, University of Calgary, Calgary, Alberta, Canada

Acknowledgements The authors would like to thank the participants of the CPC study, the CPC study team and funders of the research, including UpStart of the Calgary United Way, Alberta Health Services and Alberta Innovates-Health Solutions.

Contributors SCT was involved in the design and implementation of the CPC study. SWMD oversaw the implementation of the middle childhood follow-up as part of postdoctoral training and oversaw the analysis of the study. HKG wrote the initial draft of the paper. AEV had the primary responsibility for the final content and performed all revisions of the manuscript. All authors approved the final version.

Funding Alberta Innovates-Health Solutions, Alberta Health Services, Calgary United Way.

Competing interests None declared.

Patient consent Obtained.
Ethics approval The study received ethics approval from the Conjoint Health Research Ethics Board at the University of Calgary.

Provenance and peer review Not commissioned; externally peer reviewed.

Data sharing statement No additional data are available.

Open Access This is an Open Access article distributed in accordance with the Creative Commons Attribution Non Commercial (CC BY-NC 4.0) license, which permits others to distribute, remix, adapt, build upon this work noncommercially, and license their derivative works on different terms, provided the original work is properly cited and the use is non-commercial. See: http:// creativecommons.org/licenses/by-nc/4.0/

\section{REFERENCES}

1. Roberts KC, Shields M, de Groh M, et al. Overweight and obesity in children and adolescents: results from the 2009 to 2011 Canadian Health Measures Survey. Health Rep 2012;23:37-41.

2. Daniels SR, Arnett DK, Eckel RH, et al. Overweight in children and adolescents: pathophysiology, consequences, prevention, and treatment. Circulation 2005;111:1999-2012.

3. Mossberg HO. 40-Year follow-up of overweight children. Lancet 1989;2:491-3.

4. Must A, Jacques PF, Dallal GE, et al. Long-term morbidity and mortality of overweight adolescents. A follow-up of the Harvard Growth Study of 1922 to 1935. N Engl J Med 1992;327:1350-5.

5. Pinhas L, Morris A, Crosby RD, et al. Incidence and age-specific presentation of restrictive eating disorders in children: a Canadian paediatric surveillance program study. Arch Pediatr Adolesc Med 2011;165:895-9.

6. Bryant-Waugh R, Markham L, Kreipe RE, et al. Feeding and eating disorders in childhood. Int J Eat Disord 2010;43:98-111.

7. van Geel M, Vedder P, Tanilon J. Are overweight and obese youths more often bullied by their peers? A meta-analysis on the correlation between weight status and bullying. Int J Obesity 2014;38:1263-7.

8. Eisenberg ME, Neumark-Sztainer D, Story M. Associations of weight-based teasing and emotional well-being among adolescents. Arch Pediatr Adolesc Med 2003;157:733-8.

9. Puhl RM, King KM. Weight discrimination and bullying. Best Pract Res Clin Endocrinol Metab 2013;27:117-27.

10. Farnesi BC, Ball GD, Newton AS. Family-health professional relations in pediatric weight management: an integrative review. Pediatr Obes 2012;7:175-86.

11. Lytle LA, Hearst MO, Fulkerson J, et al. Examining the relationships between family meal practices, family stressors, and the weight of youth in the family. Ann Behav Med 2011;41:353-62.

12. Rikhy S, Tough S, Trute B, et al. Gauging knowledge of developmental milestones among Albertan adults: a cross-sectional survey. BMC Public Health 2010;10:183.

13. Lehto R, Ray C, Roos E. Longitudinal associations between family characteristics and measures of childhood obesity. Int $J$ Public Health 2012;57:495-503.

14. Moore LC, Harris CV, Bradlyn AS. Exploring the relationship between parental concern and the management of childhood obesity. Matern Child Health J 2012;16:902-8.

15. Binkin N, Spinelli A, Baglio G, et al. What is common becomes normal: the effect of obesity prevalence on maternal perception. Nutr Metab Cardiovasc Dis 2013;23:410-16.

16. Brettschneider A-K, Ellert U, Schaffrath Rosario A. Comparison of BMI derived from parent-reported height and weight with measured values: results from the German KiGGS Study. Int J Environ Res Public Health 2012:9:632-47.

17. Chaparro MP, Langellier BA, Kim LP, et al. Predictors of accurate maternal perception of their preschool child's weight status among Hispanic WIC participants. Obesity 2011;19:2026-30.

18. Doolen J, Alpert PT, Miller SK. Parental disconnect between perceived and actual weight status of children: a metasynthesis of the current research. J Am Acad Nurse Pract 2009;21:160-6.

19. He M, Evans A. Are parents aware that their children are overweight or obese? Can Fam Physician 2007;53:1493-9.

20. Hernandez RG, Cheng TL, Serwint JR. Parents' healthy weight perceptions and preferences regarding obesity counseling in preschoolers: pediatricians matter. Clin Pediatr 2010;49:790-8.

21. Jones AR, Parkinson KN, Drewett RF, et al. Parental perceptions of weight status in children: the Gateshead Millennium Study. Int $J$ Obes 2011;35:953-62.

22. Júlíusson PB, Roelants M, Markestad T, et al. Parental perception of overweight and underweight in children and adolescents. Acta Paediatr 2011;100:260-5. 
23. Kaufman-Shriqui $\mathrm{V}$, Fraser $\mathrm{D}$, Novack $\mathrm{Y}$, et al. Maternal weight misperceptions and smoking are associated with overweight and obesity in low SES preschoolers. Eur J Clin Nutr. 2012;66:216-23.

24. Lara-Garcia B, Flores-Pena Y, Alatorre-Esquivel MA, et al. Evaluation of the maternal perception of childhood overweight-obesity and maternal recognition of health risk in a Mexican border city. Salud Publica Mex 2011;53:258-63.

25. Lopes L, Santos R, Pereira B, et al. Maternal perceptions of children's weight status. Child Care Health Dev 2013;39:728-36.

26. Parry LL, Netuveli G, Parry J, et al. A systematic review of parenta perception of overweight status in children. J Ambul Care Manage 2008;31:253-68.

27. Rietmeijer-Mentink M, Paulis WD, van Middelkoop M, et al. Difference between parental perception and actual weight status of children: a systematic review. Matern Child Nutr 2013;9:3-22.

28. Warschburger P, Kroller K. Maternal perception of weight status and health risks associated with obesity in children. Pediatrics 2009;124 e60-8.

29. Warschburger P, Kroller K. Childhood overweight and obesity: maternal perceptions of the time for engaging in child weight management. BMC Public Health 2012;12:295.

30. Francescatto C, Santos NS, Coutinho VF, et al. Mothers' perceptions about the nutritional status of their overweight children: a systematic review. J Pediatr 2014;90:332-43.

31. Garrett-Wright D. Parental perception of preschool child body weight $J$ Pediatr Nurs 2011:26:435-45.

32. Tough SC, Johnston DW, Siever JE, et al. Does supplementary prenatal nursing and home visitation support improve resource use in a universal health care? A randomized controlled trial in Canada. Birth 2006;33:183-94.
33. Johnston D TS, Siever J. The Community Perinatal Care Study: home visiting and nursing support for pregnant women. Zero Three 2006;27:11-17.

34. Tough SC, Siever JE, Leew S, et al. Maternal mental health predicts risk of developmental problems at 3 years of age: follow up of a community based trial. BMC Pregnancy Childbirth 2008;8:16

35. Tough SC, Siever JE, Benzies K, et al. Maternal well-being and its association to risk of developmental problems in children at school entry. BMC Pediatr 2010;10:19.

36. Dieticians of Canada. WHO Growth Charts for Canada, 2014. http:// www.whogrowthcharts.ca (accessed 7 Jul 2014).

37. Eckstein KC, Mikhail LM, Ariza AJ, et al. Parents' perceptions of their child's weight and health. Pediatrics 2006;117:681-90.

38. Johnston JCT, McNeil DA, Best M, et al. A growth status measurement pilot in four Calgary area schools: perceptions of grade 5 students and their parents. J Sch Nurs 2011;27:61-9.

39. Stalter AM, Kaylor M, Steinke JD, et al. Parental perceptions of the rural school's role in addressing childhood obesity. J Sch Nurs 2011;27:70-81.

40. Edvardsson K, Edvardsson D, Hörnsten Å. Raising issues about children's overweight—maternal and child health nurses' experiences. J Adv Nurs 2009;65:2542-51.

41. Grimmett $\mathrm{C}$, Croker $\mathrm{H}$, Carnell $\mathrm{S}$, et al. Telling parents their child's weight status: psychological impact of a weight-screening program. Pediatrics 2008;122:e682-8.

42. Hayward KC, Ronald C. Cost of obesity in Alberta: Part 1. GPI Atlantic and Alberta Cancer Board 2009, http://www.gpiatlantic.org/ pdf/health/obesity/alberta/FinalObesityPart1.pdf.

43. Rhee KE, De Lago CW, Arscott-Mills T, et al. Factors associated with parental readiness to make changes for overweight children. Pediatrics 2005;116:e94-101. 